\title{
Comparative Evaluation of Antimicrobial Efficacy of Theobromine Toothpaste and a Low-fluoridated Toothpaste against Plaque Streptococcus mutans in Children
}

\author{
${ }^{1}$ Manjusha B Ranju, ${ }^{2}$ Madarahalli S Girish, ${ }^{3}$ Sadashivamurthy Prashanth
}

\begin{abstract}
Introduction: Cocoa bean extracts contain certain anticariogenic substances and studies have proven that it has a role in preventing dental caries. Theobromine, a white crystalline powder, is an alkaloid, readily available in cocoa and chocolate has been considered responsible for its anticariogenic activity.

Aim: The aim of the present study was to evaluate the in vivo anticaries activity of theobromine toothpaste and a commercially available low-fluoridated toothpaste against plaque Streptococcus mutans in children of age group 6 to 9 years and to evaluate the efficacy of both the toothpastes on supragingival plaque.
\end{abstract}

Materials and methods: A total of 14 subjects were selected and randomly divided into experimental and control groups $(n=7)$ in which theobromine toothpaste and a low-fluoridated toothpaste were provided. The subjects were instructed to carry out toothbrushing twice daily for 1 minute and the plaque samples were collected at baseline and after 21 days of intervention. Microbial analysis was done using selective media, mitis salivarius bacitracin (MSB) agar. The plaque index (Turesky modification of Quigley-Hein index) and gingival index (Loe and Silness) were recorded at baseline and after 21 days. The values were statistically analyzed using paired and unpaired $t$ test.

Results: There was a significant reduction in the $S$. mutans count and plaque scores from baseline to postintervention in both the groups $(p=0.001)$. When both the groups were compared, there was no significant difference in the mean S. mutans count and plaque scores $(p=0.254)$.

Conclusion: Theobromine toothpaste is highly effective in reducing $S$. mutans count and plaque formation in children.

Clinical significance: In the future, theobromine toothpaste will prove to be beneficial as a safe anticariogenic agent, which could open a new era of approach to caries prevention.

Keywords: Anticariogenic, Fluoride, Streptococcus mutans, Theobromine, Toothpaste.

\footnotetext{
${ }^{1-3}$ Department of Pedodontics and Preventive Dentistry, JSS Dental College and Hospital (Constituent College), JSS Academy of Higher Education and Research, Mysuru, Karnataka, India

Corresponding Author: Manjusha B Ranju, Department of Pedodontics and Preventive Dentistry, JSS Dental College and Hospital (Constituent College), JSS Academy of Higher Education and Research, Mysuru, Karnataka, India, Phone: +919497408595, e-mail: drranjumb@gmail.com
}

How to cite this article: Ranju MB, Girish MS, Prashanth S. Comparative Evaluation of Antimicrobial Efficacy of Theobromine Toothpaste and a Low-fluoridated Toothpaste against Plaque Streptococcus mutans in Children. World J Dent 2018;9(3):215-219.

\section{Source of support: Nil}

\section{Conflict of interest: None}

\section{INTRODUCTION}

Dental caries is a major health problem and the increasing prevalence of dental caries signals a pending public health crisis. ${ }^{1}$ Prevention and treatment efforts concerned with dental caries problems in children require further and special attention. It is because dental caries not only cause pain and discomfort but also have a significant impact on the children's quality of life and daily activities. $^{2}$ Streptococcus mutans, an acidogenic and aciduric microorganism colonizing the oral cavity, is considered to be the main cause of dental caries. ${ }^{3}$ A shift in the dynamic relationship among the dental plaque microbiota, dietary carbohydrate, saliva, and the $\mathrm{pH}$-lowering and cariogenic potential of dental plaque results in localized dissolution and destruction of the calcified tissues often resulting in cavitation. ${ }^{4}$

The prevention and control of dental caries as well as periodontal disease are dependent greatly on optimal plaque control. Mechanical plaque removal using a toothbrush twice daily, together with daily interdental cleaning, has been recommended as an effective oral hygiene regimen. ${ }^{5}$ For better plaque control, chemical inhibitors of plaque and calculus are incorporated in dentifrices and mouthwashes to enhance the effectiveness of mechanical aids employed. ${ }^{6}$ The success of any dentifrice in part lies on its ability to eliminate pathogenic oral microflora. ${ }^{7}$ Toothpaste containing fluoride are widely popular and fluorides have been historically reported to have effects against dental caries. ${ }^{8-11}$ However, it has certain drawbacks, such as toxicity and fluorosis. ${ }^{12,13}$ It is also well documented that young children who brush their teeth often ingest fluoride-containing dentifrices. ${ }^{14}$ Preventive measures which are safe for long-term use without any adverse effects should be promoted. Hence, researchers 
are keen to identify indigenous agents with enhanced anticariogenic property and reduced ill effects.

Cocoa bean extracts have been incorporated in preventing caries incidence and plaque formation. A series of studies suggested that pure cocoa powder inhibited dental caries. ${ }^{15-20}$ Theobromine is one of the major constituents in cocoa bean and studies have found that cocoa bean husk extract (CBHE) mouthwash is highly effective in reducing mutans streptococci counts and plaque deposition when used as a mouthrinse by children. ${ }^{6,21}$ The purine derivatives of cocoa powder (theobromine and caffeine) have been studied (animal studies) for its major anticariogenic property and they have found that caffeine probably had no appreciable effect. $^{22}$ This focused more on theobromine, while the research on the effect of theobromine to rebuild the hydroxyapatite in enamel is proven. ${ }^{23,24}$ Even though the effect of theobromine toothpaste on cariogenic microflora like $S$. mutans has been proven in vitro, ${ }^{7}$ the in vivo efficacy against $S$. mutans has yet to be investigated and definitely proven.

The aim of the study was to evaluate and compare the in vivo antimicrobial effect of theobromine toothpaste and a low-fluoridated toothpaste against plaque $S$. mutans in a pediatric population aged 6 to 9 years and to evaluate its efficacy on supragingival plaque.

\section{MATERIALS AND METHODS}

Theobromine toothpaste (Theodent ${ }^{\mathrm{TM}}$, United States) and a low-fluoridated commercially available kids toothpaste (Kidodent, Indoco Remedies Ltd, Mumbai) were used in the study. Pure strain of S. mutans [Microbial Type Culture Collection and Gene Bank (MTCC) 890] was obtained from MTCC, Chandigarh. The bacterium (lyophilized culture) was revived by suspending in brain heart infusion broth. The strains were cultured on MSB agar plates. ${ }^{25}$

A double-blinded study (subject and the examiner were blinded during allocation of toothpastes and plaque scoring) was conducted in 14 children of age group 6 to 9 years who came to the Department of Pedodontics and Preventive Dentistry, JSS Dental College, Mysuru, India, for their various dental needs. The study protocol was approved and ethical clearance was obtained from the institutional ethical committee. Informed consent was obtained from the parents and the study was in compliance with the code of ethics (Declaration of Helsinki).

\section{Inclusion Criteria}

- Children of age group 6 to 9 years with fully erupted first permanent molars who gave their assent and parental consent
- Children with early-stage enamel decay according to the International Caries Detection and Assessment System (ICDAS) II criteria

- Cooperative children having behavioral ratings "positive" or "definitively positive" according to Frankel's behavior rating scale

- Children who are not on any medication prior to or during the study period

- Children without any overretained deciduous teeth and mobile teeth

\section{Exclusion Criteria}

- Children with systemic diseases and medically compromising conditions

- Children undergoing orthodontic treatment or with an intraoral prosthesis

- Children who could not brush their teeth or rinse on their own

- Children who had any intraoral soft tissue pathology After obtaining the necessary consent, the toothbrushing technique (Fones Technique) was demonstrated to the subjects chosen to be a part of the study. The children were put on a washout period for 1 week wherein they were provided a common nonfluoridated toothpaste and new soft bristled, age-specific toothbrush. They were asked to refrain from the use of any oral hygiene aids other than the materials allotted in the study and were instructed to brush before breakfast and after dinner for 1 minute by using a pea-sized amount of toothpaste. The study commenced with the recording of ICDAS criteria, plaque index (Turesky modification of Quigley-Hein Index, 1970), and gingival index (Loe and Sillness 1967). ${ }^{26}$ Disclosing solution (Alpha Plac, two-tone disclosing solution) was used and the index teeth recorded were 16 , $11,64,36,41$, and $84 .^{27}$ The examination for the plaque index always preceded the examination for the gingival index. ${ }^{28}$ After recording the baseline values, the subjects were divided into two groups randomly (lottery method); group I was given theobromine toothpaste and group II was given commercially available low-fluoridated toothpaste. They were instructed to use the assigned toothpaste for 21 days and instructed to refrain from brushing the night before the dental visit in order to allow sufficient plaque accumulation.

On day 1, baseline plaque samples were collected prior to brushing without inducing bleeding. Collection of plaque samples was done from the buccal and lingual surface of 16, 11, 64, 36, 41, and 84. Plaque collection was done using an autoclaved scaler and placed in a screwcapped vial. Plaque samples were standardized using microbalance; $100 \mu \mathrm{L}$ of saline was added to each $1 \mathrm{mg}$ of plaque with the ratio being constant and vortexed. The 
Comparative Evaluation of Antimicrobial Efficacy of Theobromine Toothpaste

plaque samples were serially diluted and spread plate method was used to disperse the samples on MSB agar plates. ${ }^{25}$ Plates were stored in an anaerobic jar and incubated at $37^{\circ} \mathrm{C}$. Streptococcus mutans levels were assessed after 72 hours of incubation. Gram staining was done to confirm the presence of $S$. mutans. Estimation of the growth of $S$. mutans in colony-forming units (CFU) was carried to evaluate the cariogenic potential of the plaque. The microbial levels were checked after 21 days of usage of the intervention to test the antibacterial effect of the products. Postintervention plaque scores and gingival index scores were checked in both the groups and compared with the baseline.

\section{Counting Bacteria by Dilution and Plating}

Colonies of $S$. mutans appear with the following morphologic characteristics: $0.5 \mathrm{~mm}$ raised convex undulated colonies of light blue color with rough margins, granular frosted glass appearance. ${ }^{29}$ Plates were examined and the bacterial colonies were counted. Duplicate for each sample was used for counting the mean. The standard formula for $\mathrm{CFU}$ is:

$$
\begin{aligned}
& \frac{\mathrm{CFU}}{\mathrm{mL}}=\frac{\text { Colony count on agar plate }}{\text { Total dilution of the tube (used to make plate for }} \\
& \text { colony count) } \times \text { amount plated }
\end{aligned}
$$

\section{Statistical Analysis}

Data were analyzed using Statistical Package for the Social Sciences (version 22.0; SPSS Inc., Chicago, Illinois, USA). Paired $t$ test and independent samples $t$ test were used for statistical analysis.

\section{RESULTS}

The mean age of children in group I (theobromine toothpaste) was 7.5 and in group I (low-fluoridated toothpaste), it was 7.28.
Table 1: Colony-forming units $(\mathrm{CFU} / \mathrm{mL})$ of $S$. mutans at baseline

\begin{tabular}{llll}
\hline $\begin{array}{l}\text { Toothpaste } \\
\text { groups }\end{array}$ & Mean $\pm S D$ & Mean diff \pm SE & $p$-value \\
\hline I & $1.39 \times 10^{6} \pm 0.09 \times 10^{6}$ & $3.42 \times 10^{4} \pm 4.88 \times 10^{4}$ & $0.496^{a}$ \\
II & $1.43 \times 10^{6} \pm 0.08 \times 10^{6}$ & & \\
\hline $\mathrm{n}=7$, SE: Standard error of mean, ${ }^{\text {a Nonsignificant }}$
\end{tabular}

The results of the microbial analysis showed that the baseline $S$. mutans count was similar in both the groups, $\mathrm{p}=0.496$ (Table 1). Table 2 shows the mean $S$. mutans count $(\mathrm{CFU} / \mathrm{mL})$ in both the groups at baseline and after intervention. At baseline, the mean S. mutans CFU/mL was $1.39 \times 10^{6}$ with a standard deviation (SD) of $0.09 \times 10^{6}$ and the mean $S$. mutans $\mathrm{CFU} / \mathrm{mL}$ after intervention was $7.05 \times 10^{5}$ with an SD of $0.41 \times 10^{5}$ in theobromine group. The mean CFU/mL of $S$. mutans in low-fluoride group was $1.43 \times 10^{6}$ with an SD of $0.08 \times 10^{6}$ at baseline and after intervention, it was $7.38 \times 10^{5}$ with an SD of $0.59 \times 10^{5}$. The intragroup comparison showed a statistically significant reduction of mean $S$. mutans CFU count in both the groups. This proves that both the toothpastes are highly effective against plaque $S$. mutans.

After 21 days of toothpaste use, no significant difference was found in the mean $S$. mutans count in both the groups, $\mathrm{p}=0.254$ (Table 3 ). This proves that theobromine toothpaste is as effective as low-fluoridated toothpaste in its anti-S. mutans activity. In fact, theobromine toothpaste showed slightly more reduction in $S$. mutans count after a period of 21 days.

\section{Plaque Scores}

Plaque index scores significantly reduced from baseline to postintervention in both the toothpaste groups (Table 4). When both the toothpastes were compared based on the antiplaque action, there was no statistically significant difference, $\mathrm{p}=0.552$ (Table 5). This proves that both the toothpastes are similar in their antiplaque action.

Table 2: Intragroup comparison of CFU/mL of $S$. mutans

\begin{tabular}{lllll}
\hline Toothpaste groups & & Mean $\pm S D(C F U / m L)$ & Mean diff $\pm S D$ & $p$-value \\
\hline I & Baseline & $1.39 \times 10^{6} \pm 0.09 \times 10^{6}$ & $6.92 \times 10^{5} \pm 0.72 \times 10^{5}$ & $0.001^{\text {a }}$ \\
& Postintervention & $7.05 \times 10^{5} \pm 0.41 \times 10^{5}$ & & \\
II & Baseline & $1.43 \times 10^{6} \pm 0.08 \times 10^{6}$ & $6.94 \times 10^{5} \pm 0.32 \times 10^{5}$ & $0.001^{\text {a }}$ \\
& Postintervention & $7.38 \times 10^{5} \pm 0.59 \times 10^{5}$ & & \\
\hline
\end{tabular}

$\mathrm{n}=7$, ${ }^{\text {Highly significant }}$

Table 4: Intragroup comparison of plaque index

Table 3: Intergroup comparison of CFU/mL of S. mutans

\begin{tabular}{llll}
\hline $\begin{array}{l}\text { Toothpaste } \\
\text { groups }\end{array}$ & $\begin{array}{l}\text { Mean } \pm S D \\
(\text { CFU } / m L)\end{array}$ & Mean diff \pm SE & p-value \\
\hline I & $7.05 \times 10^{5} \pm 0.41 \times 10^{5}$ & $3.28 \times 10^{4} \pm 2.74 \times 10^{4}$ & $0.254^{a}$ \\
II & $7.38 \times 10^{5} \pm 0.59 \times 10^{5}$ & & \\
\hline $\mathrm{n}=7$, SE: Standard error of mean, ${ }^{\text {a Nonsignificant }}$
\end{tabular}

\begin{tabular}{lllll}
\hline $\begin{array}{l}\text { Toothpaste } \\
\text { groups }\end{array}$ & Mean $\pm S D$ & $\begin{array}{l}\text { Mean } \\
\text { diff } \pm S D\end{array}$ & p-value \\
\hline I & Baseline & $1.24 \pm 0.11$ & $0.21 \pm 10$ & $0.001^{\mathrm{a}}$ \\
& Postintervention & $1.02 \pm 0.04$ & & \\
II & Baseline & $1.19 \pm 0.08$ & $0.17 \pm 0.06$ & $0.001^{\mathrm{a}}$ \\
& Postintervention & $1.01 \pm 0.03$ & & \\
\hline $\mathrm{n}=7,{ }^{\text {a Highly significant }}$ & & &
\end{tabular}


Table 5: Intergroup comparison of plaque index

\begin{tabular}{llll}
\hline $\begin{array}{l}\text { Toothpaste } \\
\text { groups }\end{array}$ & Mean $\pm S D$ & Mean diff $\pm S E$ & $p$-value \\
\hline I & $1.02 \pm 0.04$ & $0.011 \pm 0.02$ & \\
II & $1.01 \pm 0.03$ & & $0.552^{\mathrm{a}}$ \\
\hline $\mathrm{n}=7$, SE: Standard error of mean, ${ }^{\text {a Nonsignificant }}$ &
\end{tabular}

Gingival index scores were taken and no significant difference was found in the mean gingival scores between day 1 and day 22 in both the groups. Gingivitis was absent in most of the children included in the study group and hence, the gingival index scores did not show any variation after 21 days of intervention.

\section{DISCUSSION}

The effect of natural compounds on the resident oral microflora, both in terms of their ability to promote the growth of beneficial organisms and by their inhibition of the growth and metabolism of species associated with disease, has been studied many times. The evolution of some innovative strategies that act against microorganisms involved in the causation of dental caries and periodontal diseases without the development of resistant microorganisms and without any adverse effects is a challenging task.

Cocoa bean husk is separated from the pre-roasted beans of Theobroma cacao. Cocoa bean naturally contains approximately 1 to $4 \%$ of theobromine. Cocoa bean husk extract has been shown to possess two types of cariostatic substances, one showing anti-GTF activity and the other, antibacterial activity. ${ }^{22,30}$ An in vitro study compared the antimicrobial activity of theobromine-containing toothpaste and two commercially available kids toothpaste and has proved that toothpaste containing theobromine showed higher antimicrobial effect against S. mutans, Lactobacillus acidophilus, and Enterococcus faecalis. ${ }^{7}$ A study done by Amaechi et $\mathrm{al}^{23}$ to identify the anticariogenic effect of theobromine by examining its ability to cause remineralization of enamel lesion concluded that theobromine in an apatite-forming medium can enhance the remineralization potential of the tooth. Sadeghpour and Carey found that theobromine protected teeth from decay better than fluoride. They found that "the amount of theobromine in an ounce dark chocolate bar has a better effect on tooth hardness than a $1.1 \%$ prescription sodium fluoride treatment," and Carey showed that at a concentration 142 times less than that of fluoride, the theobromine activity had twice the protective effect on teeth. ${ }^{31}$

The effectiveness of $\mathrm{CBHE}$ rinse in reducing $S$. mutans and plaque accumulation when used as a mouthwash by children has been proven. ${ }^{6,21}$ Studies have reported that cocoa bean extract mouthrinse can be considered as an alternative to chlorhexidine mouthrinse, as it has similar antimicrobial properties and evades the side effects of the latter. ${ }^{32}$ Another study compared chlorhexidine mouth rinse and CBHE mouth rinse with the addition of xylitol and proved that both mouth rinses are equally effective in reducing the $S$. mutans counts in saliva and reducing the plaque scores in children. ${ }^{33}$

Theobromine toothpaste contains other inactive agents, such as hydrated silica, sorbitol, xylitol, titanium dioxide, stevia extract, and sodium bicarbonate. Theobromine is more active in hydrated silica, glycerin, and xylitol. Xylitol and stevia are nonsugar sweeteners. Sodium bicarbonate is known to neutralize bacterial acids in the mouth, and titanium dioxide as a whitening agent and slight abrasive to help clean the surface of the tooth. The titanium dioxide removes the bacteria and proteins that stick to the tooth and prepares the tooth to work more effectively. Lowfluoride toothpaste composed of sodium monofluorophosphate (495 ppm) along with xylitol and its antimicrobial action is mainly attributed due to the presence of fluoride. ${ }^{7}$ Theobromine toothpaste used in this study is completely fluoride-free and the active ingredient theobromine is responsible for its superior anticariogenic action. It has been suggested that theobromine in dentifrices has no adverse effects, even if swallowed accidentally. ${ }^{14}$

\section{CONCLUSION}

With the limitations (less number of samples) of the present study, it firmly establishes the anticariogenic effect of theobromine toothpaste by the reduction of S. mutans count in dental plaque. The anticariogenic effect of theobromine has to be proven effectively with further clinical trials in vitro and in vivo.

\section{CLINICAL SIGNIFICANCE}

Theobromine could be used in future as a safe and effective alternative to fluoride in the war against dental caries and acid attack. So, it can be incorporated in oral care products other than toothpastes, such as mouthwash and chewing gum for prevention of dental caries and it probably creates a revolution in oral care.

\section{REFERENCES}

1. Bagramian RA, Garcia-Godoy F, Volpe AR. The global increase in dental caries: a pending public health crisis. Am J Dent 2009 Feb;22(1):3-8.

2. Abanto J, Carvalho TS, Fausto MM, Marcia TW, Marcelo B, Daniela PR. Impact of oral diseases and disorders on oral health-related quality of life of preschool children. Community Dent Oral Epidemiol 2011 Apr;39(2):105-114.

3. Loesche WJ. Microbiology of dental decay and periodontal disease. In: Baron S, editor. Medical microbiology [Internet]. 4th ed. Galveston (TX): University of Texas Medical Branch at Galveston; 1996 [cited 2018 Jan 23]. Available from: http:// www.ncbi.nlm.nih.gov/books/NBK8259/. 
4. Featherstone JDB. Dental caries: a dynamic disease process. Aust Dent J 2008 Sep;53(3):286-291.

5. Biesbrock A, Bartizek RD, Gerlach RW, Terézhalmy GT. Oral hygiene regimens, plaque control, and gingival health: a two-month clinical trial with antimicrobial agents. J Clin Dent 2007 Jan 1;18:101-105.

6. Dua R, KochharGK, Garewal R, Annupriyakhanna, Thakur A. Comparison of the antimicrobial efficiency of chlorhexidine and cacao bean husk extract mouth rinses in children. IOSR J Dent Med Sci 2017 Oct;16(10):50-53.

7. Arthilakshmi, Sharmin DD. Comparative evaluation on antimicrobial activity of theobromine and two commercial kids fluoride toothpaste- an in vitro study. Int J Dent Oral Health 2016;2(5):103-107.

8. Marquis RE. Antimicrobial actions of fluoride for oral bacteria. Can J Microbiol 1995 Nov;41(11):955-964.

9. Van Loveren C. The antimicrobial action of fluoride and its role in caries inhibition. J Dent Res 1990 Feb;69 Spec No:676-681.

10. Lussi A, Hellwig E, Klimek J. Fluorides-mode of action and recommendations for use. Schweiz Monatsschr Zahnmed 2012;122(11):1030-1042.

11. Buzalaf MA, Pessan JP, Honório HM, ten Cate JM. Mechanisms of action of fluoride for caries control. Monogr Oral Sci 2011;22:97-114.

12. DenBesten P, Li W. Chronic fluoride toxicity: dental fluorosis. Monogr Oral Sci 2011;22:81-96.

13. Mohanta A, Mohanty PK. Dental fluorosis—revisited. Biomed J Sci Tech Res 2018;2(1).

14. Nakamoto T, Falster A, Simmons W. Theobromine: a safe and effective alternative for fluoride in dentifrices. J Caffeine Res 2016 Jan 25.

15. Strålfors A. Inhibition of hamster caries by cocoa. Caries inhibition of water and alcohol extracts of cocoa. Arch Oral Biol 1966 Mar;11(3):323-328.

16. Strålfors A. Inhibition of dental caries in hamsters. IX. Degree of inhibition in different predilection zones. Odont Revy 1962;13:52-61.

17. Strålfors A. Inhibition of hamster caries by cocoa. The effect of whole and defatted cocoa, and the absence of activity in cowa fat. Arch Oral Biol 1966 Feb;11(2):149-161.

18. Strålfors A. Effect on hamster caries by purine derivatives vanillin and some tannin-containing materials caries in relation to food consumption and animal growth. Arch Orai Biol 1967 Mar;12(3):321-332.

19. Strålfors A. Effect on hamster caries by dialysed, detanned or carbon-treated water-extract of cocoa. Arch Oral Biol 1966 Jun;11(6):609-615.

20. Strålfors A, Keskitalo E. A method of recording dental caries in the golden hamster. A statistical study of the observation error. Odont Revy 1960;11:113-124.
21. Srikanth RK, Shashikiran ND, Subba Reddy VV. Chocolate mouth rinse: Effect on plaque accumulation and mutans streptococci counts when used by children. J Indian Soc Pedod Prev Dent 2008 Jun;26(2):67-70.

22. Osawa K, Miyazaki K, Shimura S, Okuda J, Matsumoto M, Ooshima T. Identification of cariostatic substances in the cacao bean husk: their anti-glucosyltransferase and antibacterial activities. J Dent Res 2001 Nov;80(11):2000-2004.

23. Amaechi BT, Porteous N, Ramalingam K, Mensinkai PK, Vasquez RA, Sadeghpour A, Nakamoto T. Remineralization of artificial enamel lesions by theobromine. Caries Res 2013;47(5):399-405.

24. Kargula B, Özcanb M, Pekera S, Nakamoto T, Simmons WB, Falsterd AU. Evaluation of human enamel surfaces treated with theobromine: a pilot study. Oral Health Prev Dent 2012;10(3):275-282.

25. Gold OG, Jordan HV, Van Houte J. A selective medium for Streptococcus mutans. Arch Oral Biol 1973 Nov;18(11): 1357-1364.

26. Loe $\mathrm{H}$. The gingival index, the plaque index and the retention index systems. Journal of Periodontology.1967; 38(6 part II): 610-616.

27. Mullally BH, James JA, Coulter WA, Linden GJ. The efficacy of a herbal-based toothpaste on the control of plaque and gingivitis. J Clin Periodontol 1995 Sep;22(9):686-689.

28. Ozaki F, Pannuti CM, Imbronito AV, Pessotti W, Saraiva L, de Freitas NM, Ferrari G, Cabral VN. Efficacy of a herbal toothpaste on patients with established gingivitis—a randomized controlled trial. Braz Oral Res 2006 Jun;20(2):172-177.

29. Jabbarifar SE, Tabibian SA, Poursina F. Effect of fluoride mouthrinse and toothpaste on number of streptococcal colony forming units of dental plaque. J Res Med Sci 2005;10(6): 363-367.

30. Ooshima M, Osaka Y, Sasaki H, Osawa K, Yasuda H, Matsumura M, Sobue S, Matsumoto M. Caries inhibitory activity of cocao bean husk extract in in-vitro and animal experiments. Arch Oral Biol 2000 Aug;45(2):639-645.

31. Sadhehpour A. A neural network analysis of theobromine vs fluoride on the enamel surface of human teeth. Dissertation Abstracts International, Vol. 68(07) (Suppl B), 2007; p. 150

32. Babu NS, Vivek DK, Ambika G. Comparative evaluation of chlorhexidine mouthrinse versus cacao bean husk extract mouthrinse as antimicrobial agents in children. Eur Arch Paediatr Dent 2011 Oct 1;12(5):245-249.

33. Dukle S, Patel A, Lakade L, Shah P, Lodaya R, Bha C. Comparison of chlorhexidine mouthrinse versus cacao bean husk extract mouthrinse with the addition of xylitol, as anti-plaque agents in children. Int J Curr Res 2017;9(7): 53680-53685. 